\title{
US citizens report slightly less sexual activity than in 2002
}

This news article by Janice Hopkins Tanne, which outlined the results of a US survey of 13495 men and women aged 15-44 years (BMJ 2011;342:d1500, doi:10.1136/bmj.d1500), contained errors in the data on anal and oral sex activities. The article should have said that among people aged $25-44,89 \%$ of women and $90 \%$ of men said they had ever had oral sex with a partner of the opposite sex and $36 \%$ of women and $44 \%$ of men said they had ever had anal sex with a partner of the opposite sex. The full survey report is available at www.cdc.gov/nchs/data/ nhsr/nhsr036.pdf.

Cite this as: BMJ 2011;342:d2361 